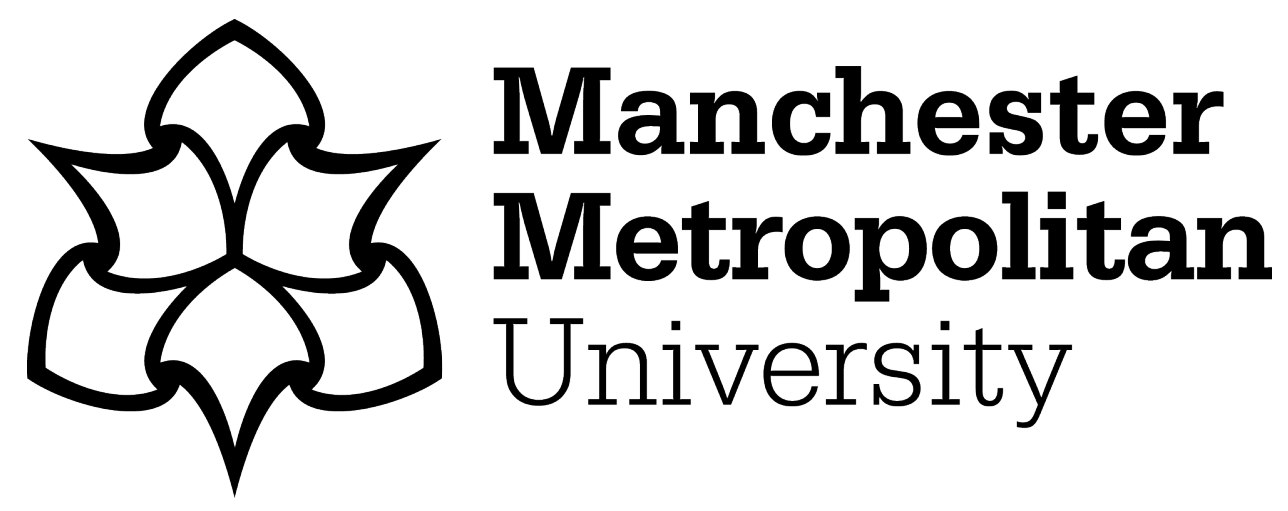

Steels, Stephanie ORCID logoORCID: https://orcid.org/0000-0001-86039069 and Simpson, Harriet (2017) Perceptions of Children in Residential Care Homes: A Critical Review of the Literature. The British Journal of Social Work, 47 (6). pp. 1704-1722. ISSN 0045-3102

Downloaded from: https://e-space.mmu.ac.uk/625097/

Version: Accepted Version

Publisher: Oxford University Press (OUP)

DOI: https://doi.org/10.1093/bjsw/bcx107

Please cite the published version 


\title{
Perceptions of Children in Residential Care Homes: A Critical Review of the Literature
}

\author{
Stephanie Steels* and Harriet Simpson
}

\author{
School of Healthcare, University of Leeds, Leeds, UK \\ *Correspondence to Dr Stephanie Steels, Room 3.30 Baines Wing, School of Healthcare, \\ University of Leeds, Leeds, LS2 9JT, UK. E-mail: Steels.Stephanie@gmail.com
}

\begin{abstract}
In England, UK, there has been an overall decline in the use of residential care for children over the years. The aim of this systematic review was to review literature concerning children placed in residential care to investigate whether this setting can meet the often complex needs of children and to explore how residential care fits in the care system today. A comprehensive search strategy was used in nine electronic databases. Studies identified were independently assessed for eligibility by two authors using a set of inclusion and exclusion criteria. Data were extracted from the final set of studies using a data-extraction tool. A thematic analysis was then conducted. The findings of the review highlighted that residential care is an important part of the care system and can have both a positive and negative effect on children's emotional, behavioural and social development, as well as their mental health and academic progress. The main recommendations from this systematic review are that staff should have further training in mental health awareness. Furthermore, there should be an increase in individual support for children, whilst attachments and bonds between staff and children should be enhanced and encouraged.
\end{abstract}

Keywords: Adolescents, children, looked after children, residential care, child development

Accepted: July 2017 


\section{Introduction}

Care planning is highlighted in recent UK government policy changes as an important feature of providing excellent care for children, with an emphasis on having an individual placement planning (Department for Education, 2011). Furthermore, there is a focus on the individuality of children and the need to observe their wishes and rights as individuals (Department for Education, 2011). The National Minimum Standards for Children's Homes has also been an influential policy in regards to raising awareness of need for quality care in children residential care homes (Berridge et al., 2012).

Additionally, children in care are expected to pursue as normal a life as possible (Hart et al., 2015). However, due to the experiences they have had and the issues they are facing, 'normality' for most children in care may be an unachievable and unrealistic expectation. Furthermore, the role of the residential care worker is more challenging at present compared to their role in the past. These range from reduced resources to provide the same level of care, to scaled-down support from other health and social care services (Berridge et al., 2012). In addition, there has been a growing number of children with a range of mental health issues (such as self-harming behaviours), challenging behaviour and interpersonal problems entering residential care (Macdonald and Millen, 2012; Andersson and Johansson, 2008). To care for children with complex needs, workers must have a good understanding of children's needs and development (Department for Education, 2011), as well the child's previous circumstances, where they may have experienced abuse of neglect (Bettmann et al., 2015). However, it is widely known that few staff members working in residential care homes have the relevant qualifications for residential practice, may lack experience and cannot easily access training to further develop their knowledge and skills (Courtney and Iwaniec, 2009).

There is a growing view that family placements are better able to meet children's needs compared to residential homes (Berridge et al., 2012). Consequently, an increased number of children with challenging behaviour, who would have been cared for in a residential care home in the past, are now placed in foster-care (Biehal, 2007). This emphasis on placing children in foster-care is concerning, as some children are fundamentally better suited to residential care. This may increase the risk of further distress in children should they be placed in an unsuitable placement.

As a result, this article provides a critical systematic review of the literature on perceptions of children in residential care. It seeks to complement other research that has been completed on looked after children (LAC) from the perspective of the child (such as Berridge et al., 2012 
and Wigley et al., 2012). In particular, this article seeks to address the following questions:

1. What are the potential positive effects for children being placed in a residential care setting?

2. What are the potential negative effects for children being placed in a residential care setting?

The structure if this paper is as follows. First, the context of LAC in England is summarised. This is followed by the literature review methodology which details the study selection criteria, the search strategy, the selection process, data extraction, methodological quality and data analysis. Then, the key findings of the thematic analysis of the literature are presented. Next, the results are discussed with reference to current social work practice. Finally, our conclusions and recommendations for social work practice and future research are presented.

\section{LAC in England}

In March 2016, there were 70,440 LAC in England (Department for Education, 2016). Children are placed in care if they are experiencing abuse, neglect or other maltreatment (Taylor and Smith, 2006; Department for Education, 2016). Furthermore, children may be placed in care voluntarily if parents are struggling to cope with the demands of parenting (Knowles and Holmstrom, 2013; NSPCC, 2016). Placement options for LAC include foster-care, children's homes, secure children's homes, hospital wards and residential schools (Davies, 2012). Residential care is a setting in which children are provided with care to encourage them to develop physically, socially and emotionally, and to promote their health and well-being (Fulcher, 2001).

The profile of children in England has changed, particularly over the last four years. In 2016, 62 per cent of LAC were aged ten years and over compared with 56 per cent in 2012 (Department for Education, 2016). This has been attributed to the increase in unaccompanied asylum-seeking children: 75 per cent are aged sixteen and over (Department for Education, 2016; Home Office, 2016). Whilst LAC are predominantly white British (75 per cent), children of mixed ethnicity are the next largest group ( 9 per cent), followed by black British ( 7 per cent), Asian or Asian British (4 per cent) and other ethnic minority groups (3 per cent). However, gender variations have varied little, with 56 per cent of LAC male and 44 per cent of LAC female in 2016 (Department for Education, 2016).

There has been an overall decline in the use of residential care for children (Hart et al., 2015). In addition to the cost implications of residential care, it has been suggested that attitudes towards residential care as a placement of preference have changed, with apprehensions about 
the absence of attachment in young children and the risk of abuse as reasons for other placement options to be considered first (Jacobs et al., 2012; Iwaniec, 2006).

As a consequence, it has been suggested that residential care is mainly used for children considered incapable of living in a family environment and is therefore viewed as a 'last resort' (Rich, 2009). This is damaging, as it gives a negative message to society that only the 'worst' children live in residential care. Children tend to have a series of unsuccessful foster placements before residential care is discussed by social services (Hart et al., 2015). It is important to note that, before being placed in residential care, children may have experienced trauma, neglect, abandonment, mental health problems, have shown antisocial behaviour and offending or have a serious medical condition (Macdonald and Millen, 2012). These issues may contribute to the reasons why children may have unsuccessful foster placements.

Attitudes that adults have today of what childhood comprises can be complex and contradictory. Children are often seen as vulnerable and in need of protection, yet also threatening and needing to be controlled (Bell, 2011). This view is very much potrayed throughout the UK care system, suggesting that there is confusion in whether children need controlling or protection, which can impact on the way in which residential care is managed. Arguably, the absence of clarity in the purpose of residential care means that it is difficult to develop appropriate provision for children in these settings (Hart et al., 2015).

Due to the number of children in care, there will unavoidably be a proportion of children with complex needs (Hart et al., 2015). Therefore, it is essential that therapeutic support or specific treatment is available to them (Hart et al., 2015). Whilst treatments may not be accessible in other placements (such as foster-care), there are an increasing number of children's homes using the 'therapeutic' title. However, the lack of an agreed definition as to what constitutes 'therapeutic residential care' makes evaluating these types of residential homes problematic (Hart et al., 2015).

Unfortunately, there still remains a large gap in provision for children with mental health issues-one that requires much more than a therapeutic milieu (Hart et al., 2015). Ultimately, a variety of services, whether in a family or residential setting, needs to be considered and established in order to meet a child's assessed needs.

\section{Methodology}

The PRISMA checklist was used to develop the systematic review protocol. A 'mixed methods' approach was used to allow both qualitative and quantitative studies to be included to maximise the range of studies that 
could be included in the review (Watkins and Gioia, 2015). To assist with structuring the research question and conducting a search of the literature, the Setting, Perspective, Intervention, Comparison and Evaluation (SPICE) model was utilised to assist in developing the search strategy and identify studies exploring attitudes, impact, knowledge and understanding (Gerrish and Lathlean, 2015). Whilst traditional systematic reviews use the PICO model (Higgins and Green, 2001), the addition of 'Evaluation' in the SPICE model can assist in the identification of qualitative papers that explore participants' attitudes to an intervention (Gerrish and Lathlean, 2015). This was important, as an initial scoping review gave insight into the breadth of research in the topic area, which had identified both qualitative and quantitative studies.

In using the SPICE model, an iterative process was used to determine the search terms of yielding potentially relevant results for each of the sections of the SPICE model. Furthermore, relevant search results titles and keywords were used to refine and develop the terms. Each section of the model became a single search string when input into the databases, which would then be combined in the final search.

Consideration of 'search sensitivity versus specificity' was also acknowledged whilst developing the search strategy. Sensitive searches aim to retrieve a high proportion of relevant studies, whilst specific searches aim to retrieve a lower proportion of irrelevant studies. A decision was made to err on the side of sensitivity, to help reduce the chances of studies being missed. As a result, rather than limiting our search strategy to research conducted in the UK, we decided to allow non-UK studies to be included in the literature search. The search strategy (Table 1) shows how search strings, truncation, wildcards and Boolean operators were used.

A total of nine databases were searched: Web of Science, ASSIA, CINAHL, IBSS, PAIS, PsychINFO, Social Services Abstracts, Social Work Abstracts and Sociological Abstracts. Reference lists from relevant review papers and any study chosen for inclusion in the review were searched to identify further relevant studies. Google scholar, Child

Table 1 Search strategy: strings used to search databases and the combination of these strings

\begin{tabular}{ll}
\hline Search strings & \\
\hline Residential care & $\begin{array}{c}\text { 'Institutional care' OR 'residential care' OR 'residential home' OR 'residential } \\
\text { treatment' OR 'residential placement' OR 'residential setting' OR 'out of } \\
\text { home' OR 'child* home' } \\
\text { Attitude* OR feeling* OR belief* OR perception* OR interpretation* OR } \\
\text { opinion* OR view* } \\
\text { Views }\end{array}$ \\
$\begin{array}{l}\text { Outcomes } \\
\text { Children }\end{array}$ & $\begin{array}{l}\text { Child* OR 'young person' OR youth OR adolescent OR infant OR 'under 18' } \\
\text { OR 'under eighteen' }\end{array}$
\end{tabular}


and Family Social Work, the British Journal of Social Work, the Department for Education (DfE) and the University of Leeds library were utilised for relevant reports, unpublished reviews and other forms of grey literature. Searches were limited by date (1 January 2005 to 31 January 2016) and language (English). Search results from each database were imported into Endnote prior to screening.

Two reviewers independently read the titles and abstracts of identified articles to determine whether they met the following inclusion criteria: articles that studied children and young people aged eighteen years and under; articles looking at children placed in residential care homes; males and females; professionals perspectives; and studies looking at children's outcomes. Any paper that did not meet the above criteria was excluded. If a consensus regarding selection decisions was not reached, then papers were discussed with a third reviewer to resolve this issue.

Overall, 1,450 studies were identified using the search strategy (Table 1); 1,318 studies were excluded due to duplications or the study title not meeting the inclusion criteria. Of the remaining 132 studies, following a read of the abstract, 104 were excluded for not meeting the inclusion criteria. Thus, twenty-eight papers were selected for full-text reading. To ascertain rigour, credibility and relevance of the articles, studies were appraised using the Critical Appraisal Skills Program (CASP) tools (Rychetnik et al., 2002). CASP have developed eight critical appraisal tools that can be used when reading research articles. These include tools for Systematic Reviews, Randomised Controlled Trials, Cohort Studies, Case Control Studies, Economic Evaluations, Diagnostic Studies, Qualitative Studies and Clinical Prediction Rule (CASP, 2017).

In total, seven papers were deemed of good quality to be included in the review (see Figure 1). Data from the papers were extracted through the use of a data-extraction tool developed by Rutter et al. (2010). Extracted data from each study included: study design, participant characteristics, sample size, outcomes and information needed for quality assessment, limitations and generalisability.

Results were analysed using a thematic method whereby two researchers independently read, re-read and coded the information from both the data-extraction forms and the articles into themes. In comparing notes, a number of different overarching themes were identified. Discrepancies in coding between the two researchers were discussed and resolved. This approach consists of using recurring themes from the selected articles to summarise and explain the findings (Popay et al., 2006; Snilstveit et al., 2012).

\section{Results}

Of the seven studies included in the final analysis (Andersson and Johansson, 2008; Harriss et al., 2008; Moreno Manso et al., 2011; 


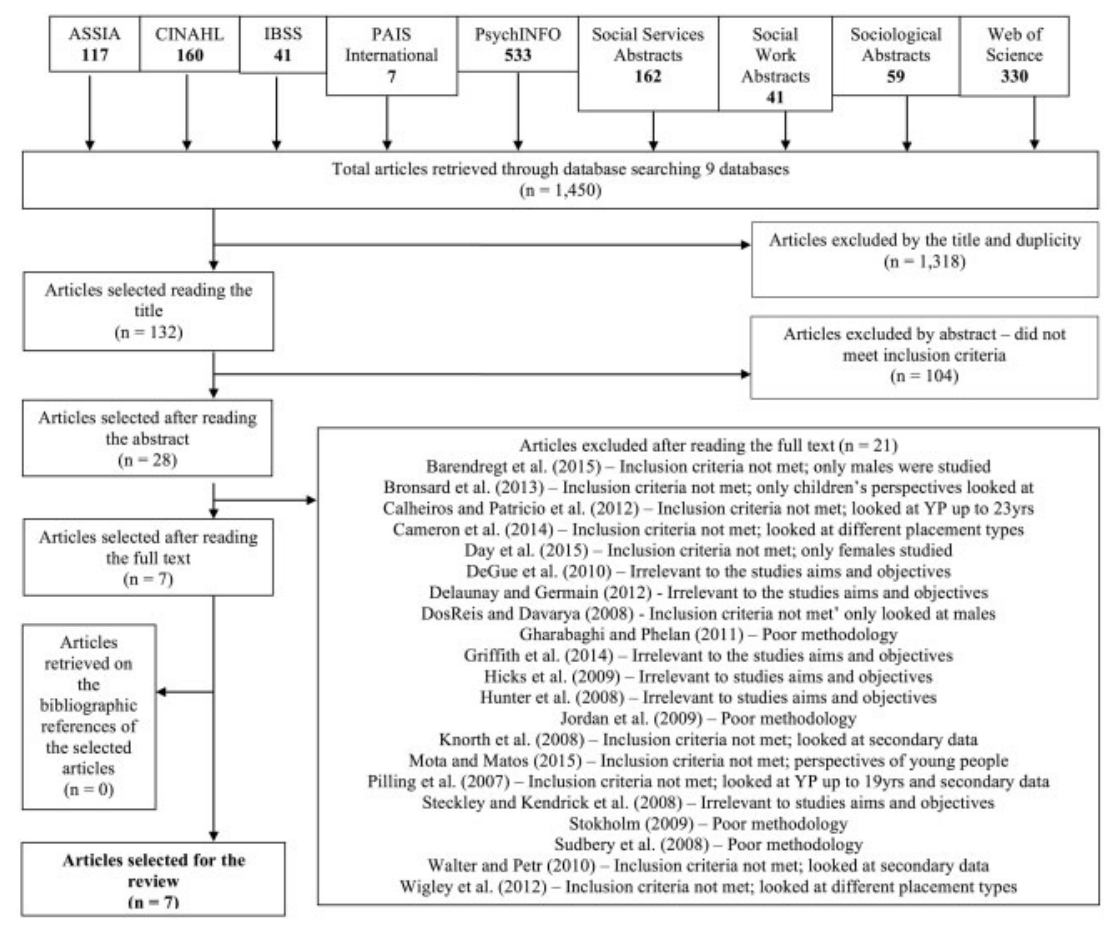

Figure 1: Flow chart of article selection

McLean, 2013; Crettenden et al., 2014; Bettmann et al., 2015; Humphreys et al., 2015), five were qualitative studies (Andersson and Johansson, 2008; Harriss et al., 2008; McLean, 2013; Crettenden et al., 2014; Bettmann et al., 2015) and two were quantitative studies (Moreno Manso et al., 2011; Humphreys et al., 2015). Five of the seven papers considered staff perspectives. Two studies produced statistical data regarding how children adapt to residential care (Moreno Manso et al., 2011) and the effects that institutional rearing has on children's psychopathology (Humphreys et al., 2015). Only one study was based in the UK (Harriss et al., 2008), whilst two studies were conducted in Australia (McLean, 2013; Crettenden et al., 2014), one in Sweden (Andersson and Johansson, 2008), one in Ghana (Bettmann et al., 2015), one in Romania (Humphreys et al., 2015) and one in Spain (Moreno Manso et al., 2011). Table 2 provides a summary of the included articles.

\section{Thematic analysis}

Whilst the included studies originate from a range of different countries (see Table 2), the thematic analysis concentrated on the contents of the 
Table 2 Summary of included studies

\begin{tabular}{|c|c|c|c|}
\hline Author and date & Country & Number of participants & Methods used \\
\hline $\begin{array}{l}\text { Andersson and } \\
\text { Johansson (2008) }\end{array}$ & Sweden & $\begin{array}{l}8 \text { residential care } \\
\text { workers }\end{array}$ & $\begin{array}{l}\text { Qualitative: semi-struc- } \\
\text { tured interviews }\end{array}$ \\
\hline Bettmann et al. (2015) & Ghana & $\begin{array}{l}92 \text { employees of eight } \\
\text { residential institutions }\end{array}$ & $\begin{array}{l}\text { Qualitative: semi-struc- } \\
\text { tured interviews }\end{array}$ \\
\hline Crettenden et al. (2014) & Australia & 32 managers & $\begin{array}{l}\text { Qualitative: interviews } \\
\text { and focus groups }\end{array}$ \\
\hline Harriss et al. (2008) & UK & 12 members of staff & $\begin{array}{l}\text { Qualitative: semi-struc- } \\
\text { tured interviews }\end{array}$ \\
\hline Humphreys et al. (2015) & Romania & $\begin{array}{l}136 \text { children and a fol- } \\
\text { low-up after } 8 \text { years } \\
\text { (110 of the } 136 \\
\text { children) }\end{array}$ & Quantitative: RCT \\
\hline McLean (2013) & Australia & 17 workers & $\begin{array}{l}\text { Qualitative: semi-struc- } \\
\text { tured interviews }\end{array}$ \\
\hline $\begin{array}{l}\text { Moreno Manso } \\
\text { et al. (2011) }\end{array}$ & Spain & 74 children & $\begin{array}{l}\text { Quantitative: } \\
\text { Autoevaluative } \\
\text { Multifactorial Child } \\
\text { Adaption Test (TAMAI) }\end{array}$ \\
\hline
\end{tabular}

studies themselves, rather than the cultural, political and geographical contexts. This was due to the decision to utilise a sensitive search strategy in keeping with the systematic nature of the literature review. Therefore, the generalisability of the findings may be reduced in terms of their application to the UK. Based on analysing the data from the studies, five themes were identified in the thematic analysis: emotional development, behavioural development, social development and relationships, mental health issues and academic progress. The following section presents the results of the critical appraisal of the included studies according to each of the above themes.

\section{Emotional development}

Children's emotional needs were an important issue highlighted by most studies (Harriss et al., 2008; Moreno Manso et al., 2011; McLean, 2013; Crettenden et al., 2014; Bettmann et al., 2015; Humphreys et al., 2015). This included bonding and attachment, which were considered important in the emotional development of the children within the residential home, particularly for those who had previously had negative experiences (Bettmann et al., 2015). Where a child was placed was also associated with both positive and negative emotional development in two studies (Harriss et al., 2008; Bettmann et al., 2015).

Elsewhere, it was noted that the support and care given by staff could have a positive influence on a child's emotional development. This included staff treating children as though they were their own (Bettmann et al., 2015) and staff making an effort to create a bond between 
themselves and the child (Harriss et al., 2008; Moreno Manso et al., 2011; McLean, 2013; Crettenden et al., 2014; Bettmann et al., 2015; Humphreys et al., 2015). Through the support of staff, in two studies, children were better able to understand the consequences of their actions and understood the impact it could have on others (Harriss et al., 2008; McLean, 2013). In trying to express their emotions, McLean's (2013) study found that there were tensions between the needs of the child expressing emotions in the form of challenging behaviour and the concern about other children in the group environment being exposed to this behaviour. Dealing with difficult emotions appeared to improve where pupils learned new strategies, such as talking and thinking about their emotions (Harriss et al., 2008).

\section{Behavioural development}

Uncertainty was a key influence in the unpredictability and inconsistency of children's behaviour (McLean, 2013; Crettenden et al., 2014; Humphreys et al., 2015). This could cause children to express their emotions through displaying challenging behaviour (McLean, 2013). It was noted that some staff felt they could not prioritise the needs of individual children, instead having to prioritise the needs of the majority of the children, which consequently reduced the opportunity of individual care (McLean, 2013). This makes it difficult to find behaviour management strategies that were reasonable to both staff and children. However, it was noted that children could respond well to the implementation of rules and boundaries, leading to the development of trust and reduction of 'difficult behaviours' (McLean, 2013; Crettenden et al., 2014).

\section{Social development and relationships}

Relationships between children and residential care staff were noted as an important factor in influencing the social development and relationship-building capabilities of children in care homes (Harriss et al., 2008; Moreno Manso et al., 2011; McLean, 2013; Bettmann et al., 2015). A positive relationship can enable children to thrive (Bettmann et al., 2015). However, several studies reported staff difficulties in maintaining relationships, particularly with young people (Andersson and Johansson, 2008; McLean, 2013).

In trying to build positive relationships with children, it was noted that staff could struggle to be both professional and caring for children as though they were their own (McLean, 2013). Elsewhere, the absence of legal authority that residential care home staff has over a child means that they struggle to impose consequences for children's behaviour. Resolving conflict without involving the child's statutory worker is 
difficult; this dynamic can result in alienation between the children and the workers (McLean, 2013). Furthermore, relationships can be difficult to form when negative behaviour is targeted at care home staff (McLean, 2013).

Several studies noted poor relationships with children in care and their peers (Harriss et al., 2008; Moreno Manso et al., 2011). Challenges in how young people and children adapt were discussed by Moreno Manso et al. (2011) and how sociability can be restricted in both girls and boys. Girls show a much more reduced amount of trust, whereas the boys are often introverts and therefore have fewer relationships (Moreno Manso et al., 2011). Where positive relationship with peers were developed, this had a positive effect on the individual by allowing the development of self-esteem (Andersson and Johansson, 2008; Harriss et al., 2008).

\section{Mental health issues}

It was noted in four studies that those who have been placed in a residential home have increased mental health issues than those who had not, which could be the result of their previous experiences and trauma before placement there (Andersson and Johansson, 2008; McLean, 2013; Crettenden et al., 2014; Humphreys et al., 2015).

The working relationships between residential staff and health care professionals was suggested as a contributory factor in increased mental health issues and, in some cases, increased the stigmatisation of children within the residential home (Andersson and Johansson, 2008; McLean, 2013; Crettenden et al., 2014). In one study, mental health workers were viewed as unable to understand behaviour in the context of the care environment (McLean, 2013). However, in children who already have mental health issues, having structure in terms of roles models, routines and procedures is significant in being able to control and protect young people from acting out and from self-destructiveness (Andersson and Johansson, 2008; Crettenden et al., 2014).

\section{Academic progress}

Within the school environment, studies reported that greater instability in a child's life was linked to reduced interest in learning and poor educational attainment (Harriss et al., 2008; Moreno Manso et al., 2011; McLean, 2013).

However, within a classroom setting with fewer students and individual attention from the staff, it was found that children were better able to concentrate, listen and be with others (Harriss et al., 2008). This equipped the children with the ability to take on more challenging work, 
learning new skills, which in turn boosted self-esteem (Harriss et al., 2008).

\section{Discussion}

The findings of this systematic literature review highlight both positive and negative effects of placing a child in a residential care setting. For some children, residential care can meet their complex needs (Thomas and Campling, 2005; Hicks, 2007; Berridge et al., 2012), enhance their lives and help them to develop as an individual within a secure and positive environment (Fleming, 2015).

However, there are negative aspects to residential care. These can vary depending on the residential home itself, the staff and their qualifications, training and experience, the other children living there and access to other services (e.g. mental health worker) (Berridge et al., 2012).

The current view in the UK that residential care is the 'end of the line' or a 'last resort' can mean that the poor outcomes associated with residential care become a self-fulfilling prophecy, as only children with severe mental health and behavioural issues are placed there (Hannon et al., 2010). Yet, for some children and young people, residential care is the most appropriate placement and could be seen as preparation for other types of long-term placement (Hart et al., 2015). This is because residential care can provide children who are not suited to adoption or fostering with an alternative placement. Residential care can facilitate the opportunity for children to build peer relationships and it can often provide stability when other placements have failed (Iwaniec, 2006; Hannon et al., 2010). Furthermore, residential care can be useful for children who have complex needs that require specialist care in the form of therapeutic support (Department for Education and Skills, 2006).

\section{What our systemic review adds to the knowledge base}

Our systematic literature review has found that there is an emphasis on the importance of creating a strong bond between staff and children. This is because children who form secure attachments are more likely to develop into socially competent adults and experience a wider range of positive life outcomes (Howe et al., 2000). Implications of insecure attachments may include: relationship difficulties, inter-personal problems, challenging behaviour, emotional and mental health problems, and poor educational achievement, all of which can adversely affect life outcomes (Hart et al., 2015).

Nevertheless, responsive and sensitive care-giving can assist in repairing attachment difficulties with time and due care (Bowlby, 1969). In 
particular, residential care can provide a number of adults for a child to connect with, which may result in an increased chance that a child will find an appropriate attachment figure (Furnivall, 2011). However, organisational and policy constraints can interfere with positive attachment making in residential care due to staff holidays, sickness, training and shift patterns (Furnivall, 2011).

Initially, children placed in residential care often experience feelings of loss, rejection and abandonment (McElwee, 2011). Staff felt that, because of this factor, children often show antisocial behaviours (Bettmann et al., 2015). The importance of staff at residential homes creating a bond with children placed there is therefore paramount (Thomas, 2005). However, it is important to note that contact with family members, permanance and good care planning should not be forgotten (Social Services Improvement Agency, 2007). Exploring the views of children who are or who have been placed in residential care in their childhood about their particular experiences would create a better understanding of how to reduce feelings of loss and abandonment.

Separation from birth parents or carers is occasionally positive, as it gives some children a better life away from their previous circumstances, where they may have experienced abuse or neglect (Bettmann et al., 2015). This is influenced by the severity of the child's situation upon entering residential care and it is likely a high proportion of children placed there are those needing the most support (Whittaker et al., 2015). It raises the issue of the outcomes of grouping children with more challenging behaviours together and what effect this can have on other individuals. Tensions can arise when a group of children are exposed to each other's extreme emotions, such as despondency and dejection, worry and anger (Clough et al., 2006). This could influence children's experiences and life outcomes, impacting on children's relationships and their ability to form such relationships (Cameron and Maginn, 2009).

However, this systematic review suggests that children in residential care settings can make positive friendships and that this can aid emotional and social development (Saha, 2006; Crettenden et al., 2014). It was noted in the literature that emotional development could be impacted positively by residential care, as these settings often provide therapeutic treatment to children (Barton et al., 2012). Therapeutic treatments such as Cognitive Behavioural Therapy (CBT) and Therapeutic Crisis Intervention (TCI) are difficult to provide in other types of placement (Adler-Tapia, 2012; Landy and Bradley, 2014), such as a home setting, as the facilities to provide this are not always available, making residential care a favourable option for these treatments (Berridge et al., 2012).

In addition, there is scope for other approaches to be utilised as part of the therapeutic treatment toolkit. For example, there has been an increase in the use of trauma-sensitive approaches in some residential care 
settings (Brown et al., 2012). By using a trauma-informed approach, residential care staff and other health and social care practitioners can focus on providing meaningful attachments for children in residential care through focusing on community reintegration (Tomlinson et al., 2011; Brown et al., 2013). This links into the growing awareness of how social pedagogical theory can be useful in meeting the needs for children in residential care. Social pedagogy in residential care is a method that considers the relationship of a young person and how they can be integrated into wider society (Cameron, 2004). Whilst, in Europe, social pedagogy underpins residential care work with children and young people (Petrie et al., 2006), this is an area that is mainly unfamiliar in the UK. Utilising interventions of 'best practice' from European practitioners, as well as pilot studies undertaken in the UK (such as Berridge et al., 2011), could lead to improved outcomes for children in residential care settings. Access to these treatments can help children to control their emotions, understand them and learn new strategies to deal with them (Barish, 2009).

However, it is important to note that placing children together who have difficulties in forming positive relationships and who lack social skills can delay or impede development because of the negative influences and lack of positive examples (Cameron and Moss, 2011). This can result in aggression and social withdrawal, which can continue to be problematic in adulthood (Schneider et al., 2012). Further research that examines why particular processes and interventions do or do not work would ensure better social work practice and improved outcomes for children in both residential care and other care settings.

Mental health was a theme that emerged in our analysis and has the potential to deteriorate when a child enters care (Bazalgette et al., 2015). However, a proportion of children who enter care have a learning disability, and therefore tend to have poorer mental health (Crettenden et al., 2014). It has been suggested that children in residential care are in the most appropriate setting when experiencing mental health issues due to the ability for trained staff to help the child in a controlled professional environment, often with twenty-four-hour care to monitor this behaviour and safeguard them from harm (Whittaker et al., 2015).

An interesting issue that was highlighted in this literature review was the conflict between 'normal' parenting and remaining professional (McLean, 2013). Staff in the residential home are seen as 'corporate parents' for the child placed there and therefore should care for the children as if they were their own (Dixon et al., 2015). This means that all aspects of their development should be nurtured, yet conflicts with the role of being a 'professional' (Butler and Hickman, 2011). Moreover, staff will have differing parenting styles and opinions on the 'correct' way to bring up a child. This can be problematic due to the lack of legal authority that residential staff have over the children they care for. This 
can result in staff not being able to discipline children, which can then lead to issues of respect and control (McLean, 2013). This further limits the ability to gain control, stability and consistency in nurturing children in residential care.

Organisational structures can also impact on the level of care given to children in residential care (Castillo et al., 2012). According to research, a high staff-to-child ratio and a high turnover of staff and young people are counterproductive (Hannon et al., 2010). A lack of attachment training, time, staff support and organisational capacity will impact on the care provided (Castillo et al., 2012). In addition, the lack of training and support offered to staff may influence the lack of communication between health and social care staff and residential staff, and thus the health needs of the child may not be met (Milligan and Stevens, 2006).

If staff lack the time and attention required to effectively care for children, addressing organisational factors may be a key part of the solution (Bettmann et al., 2015). Furthermore, a focus on the training of staff to deal with difficult behaviours and poor mental health is likely to enhance the positive outcomes for children placed in residential care (Thomas, 2005). This sets firm foundations for children to progress in all areas of development (Davies, 2011), as well as enabling staff to develop their own skills and knowledge.

This systematic literature review raises some significant questions in what can be done to enhance children's short-term outcomes in residential care and gives fresh thinking for future practice in social work to further influence positive outcomes for children in care. In particular, the authors make the following recommendations for future social work practice.

First, we recommend that social workers and residential staff should have further training in supporting children with mental health issues. This could reduce the negative perceptions that residential staff have towards outside agencies that provide mental health services and the perceived disruption that liaising with these agencies and services can cause for some children. Having a better understanding of these perceptions can allow social workers to develop better relationships with residential care staff. Additionally, further training would enable both residential staff and social workers to gain a deeper and broader understanding of the issues affecting the children they care for and the theory behind their practice.

Second, we recommend there should be increased individual support for children. Care should be child-centred and tailored to meet the needs of each individual child. More time in planning, monitoring and caring for each child would be beneficial to providing the appropriate care for varied complex needs. Assessments and treatments for children with mental health problems should place greater emphasis on talking to the service user and on understanding the problem in order to work out 
the best way to address it. When appropriate, this could be done through play.

Lastly, we recommend that residential settings should provide attachment-informed care, which would require changes in culture and policy to value and realise the therapeutic potential of relationships. In addition, investigating the perceptions of professionals as to why residential care is viewed as the 'last resort' would be beneficial to highlighting new ways of thinking about residential care and could influence a change in social work practice.

Despite the small number of studies included in this systematic analysis, this review has contributed to the understanding of perceptions of children in care homes. In particular, the use of thematic analysis further allowed a better understanding of positive and negative nuances in child development that can occur within residential care settings. However, it is important to note that these results should be interpreted with caution due to the different cultural, political and geographical contexts from these studies. Further research in exploring the positive and negative effects of placing children in residential settings would enable a better understanding of the nuances, between not only the different cultural, political and geographical contexts within a country, but also these same contexts between countries.

Furthermore, whilst our recommendations may not appear 'new', they arise from the results of our systematic review. Perhaps research focused on exploring the barriers and facilitators of implementing what could be considered 'basic practice' would enable more positive outcomes for children in residential settings. In addition, as our systematic literature review utilised studies from a variety of countries including Ghana, Sweden and Romania, perhaps there is potential for social work practitioners to learn from each other by sharing good practice across Europe and beyond.

\section{Conclusion}

In conclusion, residential care placements have been found to be both beneficial and harmful to aspects of children's development and health. This is dependent on the quality of care given and the child's initial level of need. Whilst residential care is regularly used as a 'last resort', the findings of this systematic literature review suggest that residential care can be the most appropriate placement option for many children and that many children adapt, settle and achieve positive outcomes whilst in residential care. This suggests that, although family placements are increasing and are deemed favourable to alternative placements, a small number of children are best suited to the residential environment. It is important to note that residential homes will not be valued solely by 
realising that residential care is a key part of a wider social care system. It is evident that residential work is likely to be viewed positively when the care workers are seen as skilled and experts in meeting the varied needs of children and young people.

\section{References}

Adler-Tapia, R. (2012) Child Psychotherapy: Integrating Developmental Theory into Clinical Practice, New York, Springer Publishing Company.

Andersson, B. and Johansson, J. (2008) 'Personal approaches to treatment among staff in residential care: A case study', Journal of Social Work, 8(2), pp. 117-34.

Barish, K. (2009) Emotions in Child Psychotherapy: An Integrative Framework, Oxford, Oxford University Press.

Barton, S., Gonzalez, R. and Tomlinson, P. (2012) Therapeutic Residential Care for Children and Young People: An Attachment and Trauma-Informed Model for Practice, London, Jessica Kingsley Publishers.

Bazalgette, L., Rahilly, T. and Trevelyan, G. (2015) 'Achieving emotional wellbeing for looked after children', NSPCC, available online at https://www.nspcc.org.uk/ globalassets/documents/research-reports/achieving-emotional-wellbeing-for-looked-af ter-children.pdf (accessed 6 September 2017).

Bell, M. (2011) Promoting Children's Rights in Social Work and Social Care: A Guide to Participatory Practice, London, Jessica Kingsley Publishers.

Berridge, D., Biehal, N. and Henry, L. (2012) Living in Children's Residential Homes, London, Department for Education.

Berridge, D., Biehal, N., Lutman, E., Henry, L. and Palomares, M. (2011) Raising the Bar? Evaluation of the Social Pedagogy Pilot Programme in Residential Children's Homes, London, Research Report, Department for Education.

Bettmann, J. E., Mortensen, J. M. and Akuoko, K. O. (2015) 'Orphanage caregivers' perceptions of children's emotional needs', Children and Youth Services Review, 49, 71-9.

Biehal, N. (2007) 'The uses of foster care in England: Policy, organisation and discourse', 1st International Network Foster Care Research Conference, June, Siegen, Germany.

Bowlby, J. (1969) Attachment and Loss: Attachment. V, London, Basic Books.

Brown, A. D., McCauley, K., Navalta, C. P. and Saxe, G. N. (2013) 'Trauma Systems Therapy in residential settings: Improving emotion regulation and the social environment of traumatized children and youth in congregate care', Journal of Family Violence, 28(7), pp. 693-703.

Brown, S. M., Baker, C. N. and Wilcox, P. (2012) 'Risking connection trauma training: A pathway toward trauma-informed care in child congregate care settings', Psychological Trauma: Theory, Research, Practice, and Policy, 4(5), p. 507.

Butler, I. and Hickman, C. (2011) Social Work with Children and Families: Getting into Practice, London, Jessica Kingsley Publishers.

Cameron, C. (2004) 'Social pedagogy and care: Danish and German practice in young people's residential care', Journal of Social Work, 4(2), pp. 133-51.

Cameron, C. and Moss, P. (2011) Social Pedagogy and Working with Children and Young People: Where Care and Education Meet, London, Jessica Kingsley Publishers. 
Cameron, R. and Maginn, C. (2009) Achieving Positive Outcomes for Children in Care, London, Sage.

Castillo, J. T., Sarver, C. M., Bettmann, J. E., Mortensen, J. and Akuoko, K. (2012) 'Orphanage caregivers' perceptions: The impact of organizational factors on the provision of services to orphans in the Ashanti Region of Ghana', Journal of Children and Poverty, 18(2), pp. 141-60.

Clough, R., Bullock, R. and Ward, A. (2006) What Works in Residential Child Care, London, Jessica Kingsley Publishers.

Courtney, M. E. and Iwaniec, D. (2009) Residential Care of Children: Comparative Perspectives, New York, Oxford University Press.

Crettenden, A., Wright, A. and Beilby, E. (2014) 'Supporting families: Outcomes of placement in voluntary out-of-home care for children and young people with disabilities and their families', Children and Youth Services Review, 39, pp. 57-64.

Critical Appraisal Skills Programme (CASP) (2017) 'About CASP checklists', last updated January 2017, available online at http://www.casp-uk.net/casp-tools-check lists (accessed 6 September 2017).

Davies, D. (2011) Child Development: A Practitioner's Guide, New York, Guilford Press.

Davies, M. B. (2012) Social Work with Children and Families: Policy, Law, Theory, Research and Practice, Basingstoke, Palgrave Macmillan.

Department for Education (2011) Children's Homes: National Minimum Standards, London, Department for Education.

Department for Education (2016) 'Children looked after in England (including adoption and care leavers) year ending 31 March 2016', London, Department for Education.

Department for Education and Skills (2006) Care Matters: Transforming the Lives of Children and Young People in Care, London, HMSO.

Dixon, J., Lee, J., Stein, M., Guhirwa, H., Bowley, S. and Catch22 NCAS Peer Researchers (2015) Corporate Parenting for Young People in Care: Making the Difference?, York, University of York.

Fleming, R. (2015) 'Towards belonging: Negotiating new relationships for adopted children and those in care', Journal of Child Psychotherapy, 41(3), pp. 323-8.

Fulcher, L. (2001) 'Differential assessment of residential group care for children and young people', British Journal of Social Work, 31(3), pp. 417-35.

Furnivall, J. (2011) Attachment-Informed Practice with Looked After Children and Young People, Glasgow, Institute for Research and Innovation in Social Services.

Gerrish, K. and Lathlean, J. (2015) The Research Process in Nursing, Oxford, Wiley Blackwell.

Hannon, C., Wood, C. and Bazalgette, L. (2010) In Loco Parentis: To Deliver the Best for Looked After Children, the State Must Be a Confident Parent ..., London, Demos.

Harriss, L., Barlow, J. and Moli, P. (2008) 'Specialist residential education for children with severe emotional and behavioural difficulties: Pupil, parent, and staff perspectives', Emotional \& Behavioural Difficulties, 13(1), pp. 31-47.

Hart, D., La Valle, I. and Holmes, L. (2015) The Place of Residential Care in the English Child Welfare System, Loughborough, Department for Education.

Hicks, L. (2007) Managing Children's Homes: Developing Effective Leadership in Small Organisations, London, Jessica Kingsley Publishers. 
Higgins, J. P. T. and Green, S. (eds) (2001) Cochrane Handbook for Systematic Reviews of Interventions Version 5.1.0, updated March 2011, The Cochrane Collaboration, 2011, available online at www.handbook.cochrane.org (accessed 6 September 2017).

Home Office (2016) 'Home Office National Statistics asylum data tables', available online at https://www.gov.uk/government/publications/immigration-statistics-april-tojune-2016/list-of-tables (accessed 6 September 2017).

Howe, D., Dooley, T. and Hinings, D. (2000) 'Assessment and decision-making in a case of child neglect and abuse using an attachment perspective', Child and Family Social Work, 5(2), pp. 143-56.

Humphreys, K. L., Gleason, M. M., Drury, S. S., Miron, D., Nelson, C. A., III, Fox, N. A. and Zeanah, C. H. (2015) 'Effects of institutional rearing and foster care on psychopathology at age 12 years in Romania: Follow-up of an open, randomised controlled trial', Lancet Psychiatry, 2(7), pp. 625-34.

Iwaniec, D. (2006) The Child's Journey through Care: Placement Stability, Care Planning, and Achieving Permanency, Chichester, John Wiley \& Sons.

Jacobs, C., Ilan-Clarke, Y. and Bifulco, A. (2012) 'Caring about attachment in young people in residential care: The use of the Attachment Style Interview', Community Care.

Knowles, G. and Holmstrom, R. (2013) Understanding Family Diversity and Home-School Relations: A Guide for Students and Practitioners in Early Years and Primary Settings, London, Routledge.

Landy, S. and Bradley, S. (2014) Children with Multiple Mental Health Challenges: An Integrated Approach to Intervention, New York, Springer Publishing Company.

Macdonald, G. and Millen, S. (2012) Therapeutic Approaches to Social Work in Residential Child Care Settings: Literature Review, Belfast, Northern Ireland, Social Care Institute for Excellence (SCIE).

McElwee, N. (2011) At-Risk Children \& Youth: Resiliency Explored, Oxon, Routledge.

McLean, S. (2013) 'Managing behaviour in child residential group care: Unique tensions', Child \& Family Social Work, 20(3), pp. 344-53.

Milligan, I. and Stevens, I. (2006) Residential Child Care: Collaborative Practice, London, Sage.

Moreno Manso, J. M., Elena Garcia-Baamonde, M., Blazquez Alonso, M. and Guerrero Barona, E. (2011) 'An analysis of how children adapt to residential care', Children and Youth Services Review, 33(10), pp. 1981-8.

NSPCC (2016) Children in Care: Our Work with Looked After Children, the Challenges in Care and What the Law Says, London, NSPCC.

Petrie, P., Boddy, J. and Cameron, C. (2006) Working with Children in Care: European Perspectives: European Perspectives, Berkshire, McGraw-Hill Education (UK).

Popay, J., Roberts, H., Sowden, A., Petticrew, M., Arai, L., Rodgers, M., Britten, N., Roen, K. and Duffy, S. (2006) 'Guidance on the conduct of narrative synthesis in systematic reviews', a product from the ESRC methods programme, Version, 1.

Rich, J. (2009) 'Labels that disable-meeting the complex needs of children in residential care', British Journal of Special Education, 36(1), pp. 3-8.

Rutter, D., Francis, J., Coren, E. and Fisher, M. (2010) SCIE systematic research reviews: guidelines, London, Social Care Institute for Excellence. 
Rychetnik, L., Frommer, M., Hawe, P. and Shiell, A. (2002) 'Criteria for evaluating evidence on public health interventions', Journal of Epidemiology and Community Health, 56, pp. 119-27.

Saha, J. (2006) Management and Organizational Behaviour, New Delhi, Excel Books India.

Schneider, B., Attili, G., Nadel, J. and Weissberg, R. (2012) Social Competence in Developmental Perspective, Dordrecht, Springer Science \& Business Media.

Snilstveit, B., Oliver, S. and Vojtkova, M. (2012) 'Narrative approaches to systematic review and synthesis of evidence for international development policy and practice', Journal of Development Effectiveness, 4(3), pp. 409-29.

Social Services Improvement Agency (2007) 'What works in promoting good outcomes for looked after children and young people?', Child and Family Social Work, 5(1), pp. 79-86.

Taylor, C. and Smith, D. (2006) Young People in Care and Criminal Behaviour, London, Jessica Kingsley Publishers.

Thomas, N. (2005) 'Social work with young people in care: Looking after children in theory and practice', Social Work \& Social Sciences Review, 12(1), pp. 72-3.

Thomas, N. and Campling, J. (2005) Social Work with Young People in Care: Looking after Children in Theory and Practice, London, Palgrave Macmillan.

Tomlinson, P., Gonzalez, R. and Barton, S. (2011) Therapeutic Residential Care for Children and Young People: An Attachment and Trauma-Informed Model for Practice, London, Jessica Kingsley Publishers.

Watkins, D. and Gioia, D. (2015) Mixed Methods Research, New York, OUP.

Whittaker, J., Del Valle, J. F. and Holmes, L. (2015) Therapeutic Residential Care for Children and Youth: Developing Evidence-Based International Practice, London, Jessica Kingsley Publishers.

Wigley, V., Preston-Shoot, M., McMurray, I. and Connolly, H. (2012) 'Researching young people's outcomes in children's services: Findings from a longitudinal study', Journal of Social Work, 12, pp. 573-94. 